\title{
Estudio comparativo de perfiles de disolución de tabletas de prednisona 20 mg comercializados en Perú
}

\author{
Luis Antonio Martín Casanova-Godoy ${ }^{1}$, ${ }^{*}$ Ericson Félix Castillo-Saavedra ${ }^{1}$, Elva Milagros Reynoso-Leyva ${ }^{1}$, \\ Carmen Isolina Ayala-Jara ${ }^{1}$ \\ IUniversidad Nacional de Trujillo, Facultad de Farmacia y Bioquímica. Trujillo, Perú
}

Cómo referenciar este artículo/

How to reference this article:
Casanova-Godoy LAM, Castillo-Saavedra EF, Reynoso-Leyva EM, Ayala-Jara CI. Estudio comparativo de perfiles de disolución de tabletas de prednisona $20 \mathrm{mg}$ comercializados en Perú. Mem. Inst. Investig. Cienc. Salud. 2018; 16(3): 13-21

\section{RE S U M E N}

El estudio tuvo como finalidad comparar los perfiles de disolución de tabletas de prednisona $20 \mathrm{mg}$ comercializados en Perú. Se realizó un estudio cuantitativo comparativo con diseño no experimental, que incluyó doce tabletas para cada formulación a evaluar (referente y multifuente), bajo condiciones similares de trabajo, en tres medios de disolución: buffer ácido clorhídrico pH 1,2; buffer acetato $\mathrm{pH} 4,5$ y buffer fosfato $\mathrm{pH} 6,8$. Los porcentajes temporales disueltos de prednisona fueron evaluados mediante el orden cinético cero, uno, Higuchi, raíz cúbica y Weibull para el modelo dependiente; mientras que el factor de similitud $\left(f_{2}\right)$, tiempo medio de disolución y eficiencia de disolución fueron utilizados para el modelo independiente. En el modelo dependiente, la liberación de prednisona; se ajustó a la cinética de función de Weibull; evaluada mediante el criterio de información de Akaike. En el modelo independiente, los valores de $\mathrm{f}_{2}$ en todos los medios de disolución cumplieron con el rango 50 - 100 establecida por la Food and Drug Adminstration, para indicar similitud in vitro entre los perfiles de disolución. Asimismo, se evidenció que no existe diferencia estadísticamente significativa entre las formulaciones, respecto al tiempo medio de disolución y la eficiencia de disolución. Las tabletas de prednisona $20 \mathrm{mg}$ referente y multifuente comercializados en Perú son similares, con base en pruebas de perfiles de disolución in vitro.

Palabras clave: disolución, prednisona, liberación de fármaco, técnicas in vitro (Fuente: DeCS BIREME).

\section{Comparative study of dissolution profiles of prednisone $\mathbf{2 0}$ mg tablets marketed in Peru}

\section{A B S T R A C T}

The purpose of the study was to compare the dissolution profiles of prednisone $20 \mathrm{mg}$ tablets marketed in Peru. A comparative quantitative study with a non-experimental design was carried out, which included twelve tablets for each formulation to be evaluated (referent and multi-source), under similar work conditions in three dissolution media: hydrochloric acid buffer $\mathrm{pH} 1.2$, acetate buffer $\mathrm{pH} 4.5$ and phosphate buffer $\mathrm{pH} 6.8$. The dissolved temporal percentages of prednisone were evaluated by zero kinetic order and first kinetic order, Higuchi, cubic root and Weibull models for the dependent model; while the similarity factor (f2), mean dissolution time and dissolution efficiency were used for the independent model. In the dependent model, the release of prednisone was adjusted to the Weibull function kinetics, evaluated using the Akaike information criterion. In the independent model, the values of $\mathrm{f} 2$ in all the dissolution media fulfilled the range $50-100$ established by the Food and Drug Administration, to indicate in vitro similarity between the dissolution profiles. Likewise, it was evidenced that there is no statistically significant 
difference between the formulations with respect to the mean dissolution time and the dissolution efficiency. The reference and multi-source prednisone $20 \mathrm{mg}$ tablets marketed in Peru are similar based on in vitro dissolution profiles tests.

Keywords: dissolution, prednisone, drug release, in vitro techniques (Source: MeSH NLM).

\section{INTRODUCCIÓN}

En la actualidad, nuestro país carece de medicamentos genéricos que aseguren un tratamiento terapéutico eficaz a la población, solo existen medicamentos similares que no han sido sometidos a estudios de bioequivalencia, por lo que no se podría establecer intercambiabilidad con el medicamento innovador, que fue aquel que salió primero al mercado y que recibió la autorización de comercialización por la demostración de eficacia y seguridad con base en ensayos clínicos ${ }^{(1)}$.

La intercambiabilidad se fundamenta en que dos equivalentes farmacéuticos son bioequivalentes, cuando las concentraciones del fármaco se equilibran en el organismo sincrónicamente, por lo tanto, la evolución de las concentraciones en la biofase va a ser prácticamente la misma para ambos productos (multifuente e innovador) ${ }^{(2)}$.

La prueba de disolución in vitro es utilizada en el desarrollo y evaluación de medicamentos para proporcionar control del proceso y aseguramiento de la calidad, así como determinar las características de liberación de estabilidad del producto a lo largo del tiempo, y de esta manera cumplir con parámetros de identificación, pureza, y, bioequivalencia en el caso de productos farmacológicos intercambiables ${ }^{(3,4)}$.

La bioequivalencia in vitro busca establecer correlaciones in vitro - in vivo, de tal forma que una prueba de disolución pueda reemplazar la disposición del medicamento cuando es administrado en el ser humano, con la finalidad de obtener equivalentes biofarmacéuticos entre un medicamento innovador y multifuente, se utilizan 12 unidades de dosificación y se colocan en medios agitados con diferentes tipos de $\mathrm{pH}(1,2 ; 4,5$ y 6,8$)$, que simulan las condiciones del tránsito del medicamento desde el inicio de la administración, que se analizan generalmente mediante cromatografía o espectroscopia ultravioleta ${ }^{(5-7)}$.

La similitud de los perfiles de disolución para fines de intercambiabilidad se determina mediante el método de modelo independiente del factor de similitud $\left(f_{2}\right)$, que debe considerar por lo menos 3 puntos de muestreo para cada medio de disolución, y debe presentar un valor comprendido entre 50 - 100. Asimismo, el ajuste de los porcentajes de la evolución temporal del fármaco se realiza mediante el modelo dependiente, e incluye el orden cero, primer orden, Higuchi, raíz cúbica y Weibull ${ }^{(3,8,9)}$.

La prednisona es un glucocorticoide utilizado en la práctica clínica, y se prescribe en enfermedades inflamatorias en forma de tabletas orales de liberación inmediata en presentaciones de 5,20 y $50 \mathrm{mg}$, pertenece a la clase 1 , de acuerdo al Sistema de Clasificación Biofarmacéutica (SCB), y sólo debe demostrar equivalencia terapéutica in vitro para demostrar su intercambiabilidad entre el medicamento multifuente y referente ${ }^{(10,11)}$.

La United States Pharmacopeia (USP) 41 establece como criterio de aceptación un contenido no menor del $90 \%$ y no más del $110 \%$ de la cantidad declarada para tabletas que declaran contener más de $10 \mathrm{mg}$ de prednisona, y para el ensayo de disolución establece una tolerancia de no menos del 80\% (Q) a los 30 minutos, utilizando como medio agua 900 $\mathrm{mL}$, aparato tipo paleta a $50 \mathrm{rpm}$, en modo ultravioleta a $242 \mathrm{~nm}$ de lectura ${ }^{(12)}$.

En el Perú, no existen estudios publicados que reporten los perfiles de disolución de prednisona, por lo que, la realización de este tipo de tendría implicancias en los sistemas de salud de la población peruana, al poder tener un producto eficaz y seguro a un precio menor.

El estudio tuvo como propósito comparar los perfiles de disolución de tabletas de prednisona $20 \mathrm{mg}$ comercializados en Perú, y de esta manera poder establecer intercambiabilidad entre la formulación de referencia y multifuente.

\section{MATERIAL Y MÉTODOS}

El estudio fue cuantitativo comparativo con diseño no experimental, y se utilizaron 50 tabletas de la formulación referente y multifuente de prednisona $20 \mathrm{mg}$ procedentes del mismo lote y con fecha de vencimiento similar.

Las curvas de calibración fueron preparadas a partir de un estándar secundario de prednisona para los tres medios de disolución (buffer $\mathrm{pH} 1,2$; buffer $\mathrm{pH} 4,5$ y buffer $\mathrm{pH}$ 
$6,8)$. Se preparó el estándar de prednisona mediante un estudio piloto. Se pesaron $25 \mathrm{mg}$ de estándar de prednisona y se colocaron en un matraz aforado de $250 \mathrm{~mL}$ y se procedió a aforar. Finalmente se filtraron las muestras y se realizaron lecturas a una longitud de onda de $242 \mathrm{~nm}$.

El ensayo de disolución para los tres medios utilizó doce tabletas para cada formulación referencia y multifuente, y se siguieron los lineamientos establecidos por la USP 40: aparato tipo II, $50 \mathrm{rpm}$, volumen de agua $900 \mathrm{~mL}$, temperatura $37^{\circ} \mathrm{C} \pm 0,5{ }^{\circ} \mathrm{C}$. Se tomaron alícuotas filtradas de $10 \mathrm{~mL}$ sin reposición en diferentes tiempos (5, 10, 15, 30, 45 y 60 minutos). Posteriormente se realizaron lecturas en el espectrofotómetro ultravioleta a $242 \mathrm{~nm}$. Las concentraciones se determinaron a partir de las curvas estándares previamente elaboradas ${ }^{(12)}$.

Los modelos dependientes permitieron establecer el mejor ajuste de los datos de los porcentajes de fármaco disuelto, mediante el Criterio de Información Akaike (AIC), y a partir del mejor modelo cinético para cada lote y $\mathrm{pH}$ se determinaron sus constantes de velocidad de disolución ${ }^{(13-15)}$.

Los modelos independientes se establecieron mediante el cálculo de $f_{2}{ }^{(15)}$, y según lo establecido por la Food and Drug Administration (FDA) que sugiere que dos perfiles de disolución se considerarán similares si el valor se sitúa entre 50 y $100^{(7)}$.

El tiempo medio de disolución (TMD) se calcula a partir de las curvas acumulativas de las cantidades disueltas de fármaco en función al tiempo mediante la ecuación, y es el tiempo promedio de residencia del principio activo en la forma farmacéutica. La eficiencia de disolución (ED\%) se calcula a partir de los valores obtenidos del área bajo la curva ( $A B C$ ) del perfil de disolución para cada intervalo de tiempo, a través del método de los trapezoides ${ }^{(13)}$.

Los parámetros evaluados fueron caracterizados mediante estadísticos descriptivos, media aritmética y coeficiente de variación porcentual. Los promedios de las constantes de disolución para cada formulación y para cada $\mathrm{pH}$ fueron sujetos a un análisis $\mathrm{t}$ de Student con un nivel de confianza del $5 \%(\alpha=0,05)^{(5,6)}$.

\section{RESULTADOS}

En la Figura 1 se reportan los porcentajes de disolución de las tabletas de prednisona 20 mg hasta los 60 minutos a buffer $\mathrm{pH} \mathrm{1,2;} \mathrm{evidenciando} \mathrm{una} \mathrm{similitud} \mathrm{en} \mathrm{los} \mathrm{perfiles} \mathrm{del}$ producto referente y multifuente, en los primeros puntos de muestreo los porcentajes son pequeños y se van incrementando en función del tiempo hasta que finalmente se vuelve constante.

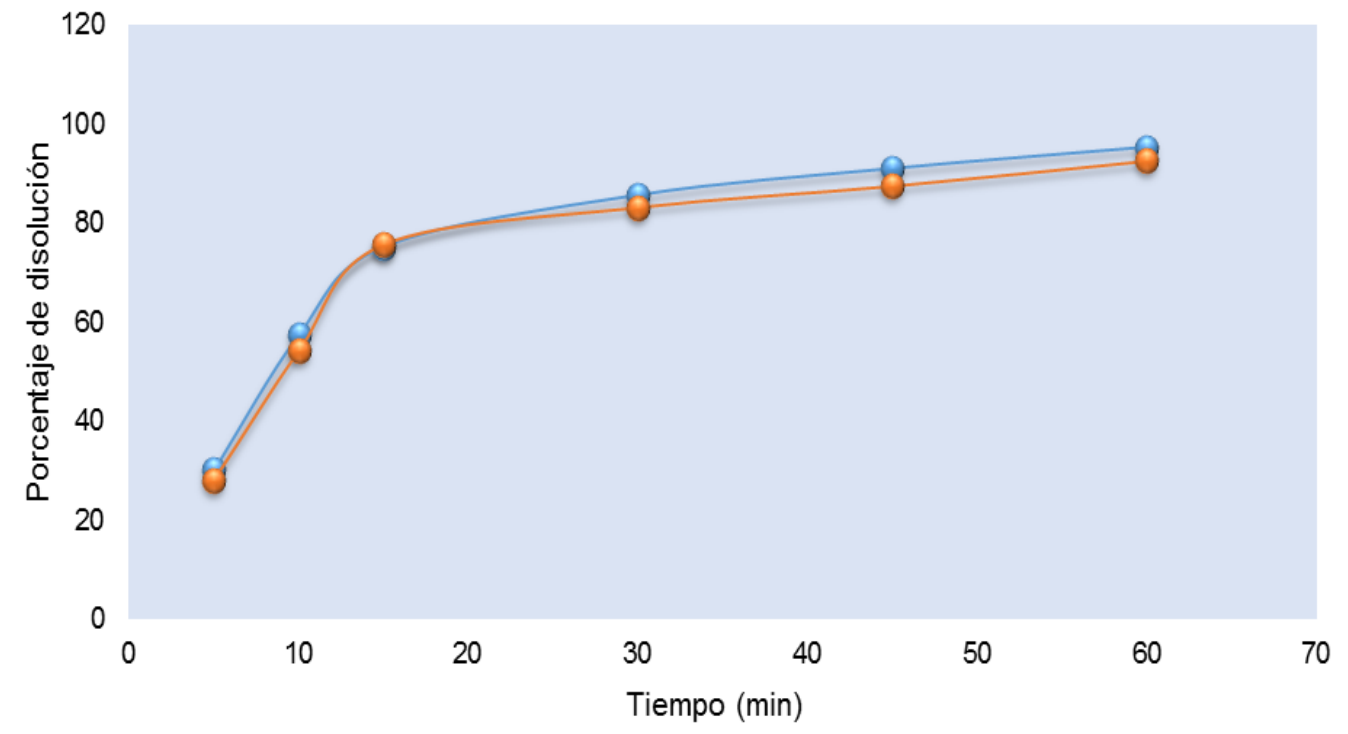

- referente - multifuente

Figura 1. Perfiles de disolución de prednisona $20 \mathrm{mg}$ referencia y multifuente a pH 1,2. 
En la Figura 2, a buffer $\mathrm{pH}$ 4,5 los perfiles de disolución presentan similitudes en los porcentajes disueltos, lo que evidenciaría una primera fase de liberación con incremento en los coeficientes de variación porcentual, y a medida que se incrementa el tiempo se observa una mayor cantidad de fármaco disuelto con un menor coeficiente de variación porcentual.

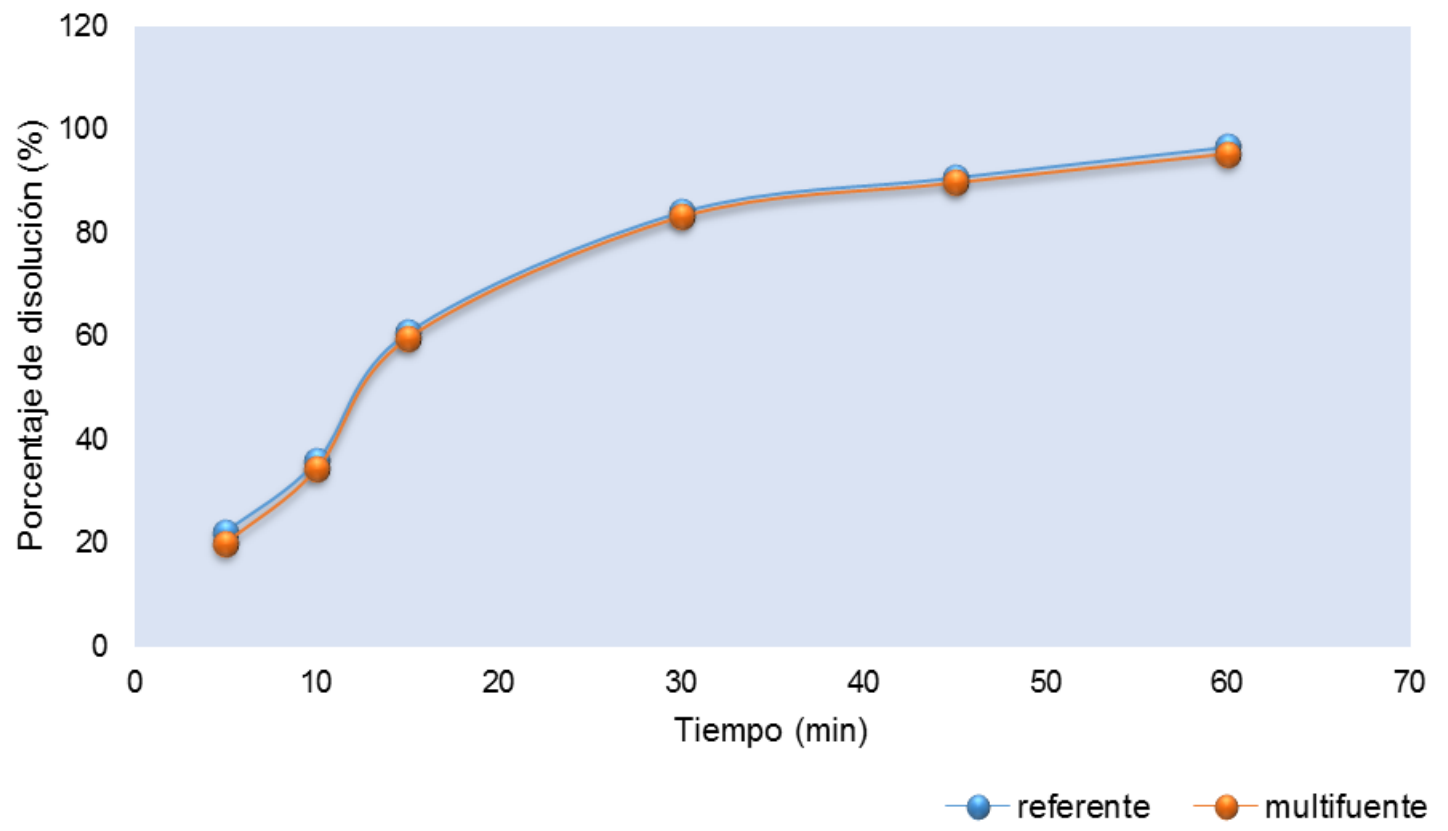

Figura 2. Perfiles de disolución de prednisona $20 \mathrm{mg}$ referencia y multifuente a pH 4,5.

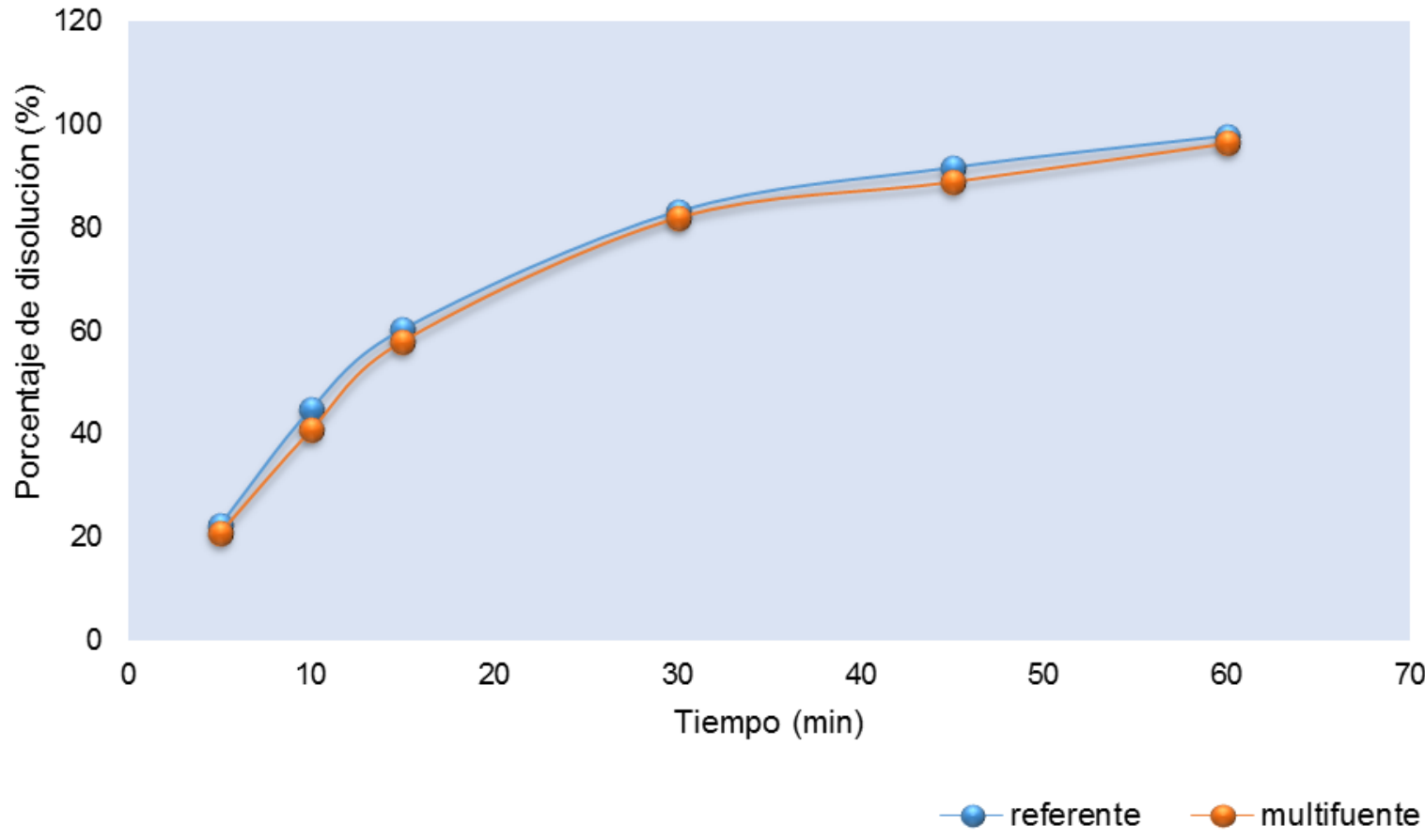

Figura 3. Perfiles de disolución de prednisona 20 mg referencia y multifuente a pH 6,8.

En la Figura 3, la tendencia de los perfiles de disolución en función del tiempo a buffer pH 6,8 se hacen constantes a los 60 minutos con similitudes en los porcentajes disueltos, lo que demostraría el compromiso que presentan las industrias farmacéuticas peruanas en el proceso de manufactura de sus medicamentos, utilizando principios activos y excipientes con las mismas exigencias que los laboratorios transnacionales, asegurando eficacia terapéutica en el paciente. 
En la Tabla 1 se puede observar que los porcentajes promedio de fármaco disuelto en función del tiempo siguen una cinética de Weibull según el Criterio de Información de Akaike, el cual evalúa el valor más pequeño en $\operatorname{los} \mathrm{pH} 1,2 ; 4,5$ y 6,8 tanto para referente y multifuente.

Tabla 1. Criterio de Información de Akaike para la cinética de disolución de las tabletas de prednisona $20 \mathrm{mg}$ referente y multifuente a $\mathrm{pH} 1,2 ; 4,5$ y 6,8 .

\begin{tabular}{lllllll}
\hline \multirow{2}{*}{ Modelo } & pH 1,2 & \multicolumn{3}{c}{ pH 4,5 } & \multicolumn{3}{c}{ pH 6,8 } \\
\cline { 2 - 7 } & Referente & Multifuente & Referente & Multifuente & Referente & Multifuente \\
\hline $\begin{array}{l}\text { Orden } \\
\text { Cero }\end{array}$ & 43,8 & 44,2 & 42,1 & 42,7 & 40,7 & 40,7 \\
$\begin{array}{l}\text { Orden } \\
\text { Uno }\end{array}$ & $-3,12$ & $-1,3$ & $-4,4$ & $-4,6$ & $-5,9$ & $-10,7$ \\
$\begin{array}{l}\text { Raíz } \\
\text { Cúbica }\end{array}$ & 42,1 & 35,5 & 44,5 & 40,1 & 47,5 & 41,8 \\
$\begin{array}{l}\text { Higuchi } \\
\text { Weibull }\end{array}$ & $-22,0$ & 22,6 & 19,4 & 18,7 & 16,4 & 16,5 \\
(*) & $-3,2$ & $-2,1$ & $-5,8$ & $-5,3$ & $-13,2$ & $-11,1$ \\
\hline
\end{tabular}

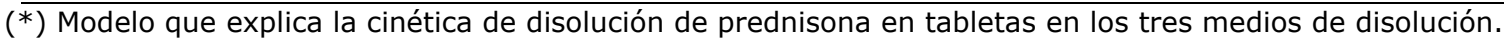

En la Tabla 2 se analiza estadísticamente el tiempo medio de disolución de las tabletas de prednisona $20 \mathrm{mg}$ referente y multifuente a $\mathrm{pH} 1,2 ; 4,5$ y 6,8; para lo cual se realizó en primer lugar la normalidad de los datos mediante la prueba Shapiro Wilk; posteriormente, se evaluó diferencia significativa mediante la prueba t student, y se encontró que en los tres medios de disolución no es significativo, por lo que se asumiría igualdad en las medias para el producto referente y multifuente.

Tabla 2. Tiempo medio de disolución de las tabletas de prednisona $20 \mathrm{mg}$ referente y multifuente a pH 1,$2 ; 4,5$ y 6,8 .

\begin{tabular}{lllllll}
\hline $\begin{array}{l}\text { Tiempo } \\
\text { medio de } \\
\text { disolución }\end{array}$ & pH 1,2 & \multicolumn{3}{c}{ pH 4,5 } & \multicolumn{3}{c}{ pH 6,8 } \\
\cline { 2 - 7 } & Referente & Multifuente & Referente & Multifuente & Referente & Multifuente \\
\hline Promedio & 10,1 & 9,9 & 15,9 & 16,1 & 16,2 & 16,6 \\
D.E. & 0,8 & 0,9 & 1,2 & 1,3 & 0,7 & 1,0 \\
C.v. \% & 8,7 & 9,3 & 7,5 & 8,3 & 4,7 & 6,0 \\
t student & $-1,0$ & & $-0,4$ & & $-1,2$ & \\
\hline
\end{tabular}

(*) El valor es significativo a nivel de 0,05 y grados de libertad 22.

De la misma manera, en la tabla 3 se analiza la eficiencia de disolución de las tabletas de prednisona $20 \mathrm{mg}$ referente y multifuente a $\mathrm{pH} 1,2 ; 4,5$ y 6,8; habiendo comprobado en primer término la normalidad de los datos con la prueba de Shapiro wilk, y finalmente no se encontró diferencia estadísticamente significativa en los tres medios de disolución mediante la prueba t de student. En este sentido, se asumiría igualdad entre el producto referente y multifuente. 
Tabla 3. Eficiencia de disolución de las tabletas de prednisona $20 \mathrm{mg}$ referente y multifuente a pH 1,$2 ; 4,5$ y 6,8 .

\begin{tabular}{lllllll}
\hline $\begin{array}{l}\text { Eficiencia } \\
\text { de } \\
\text { disolución }\end{array}$ & pH 1,2 & & RH 4,5 & \multicolumn{3}{c}{ pH 6,8 } \\
\cline { 2 - 7 } & Referente & Multifuente & Referente & Multifuente & Referente & Multifuente \\
\hline Promedio & 71,9798 & 71,7346 & 62,2227 & 61,2308 & 61,1460 & 60,6666 \\
D.E. & 2,8024 & 1,7600 & 0,7942 & 0,7467 & 0,8866 & 0,6867 \\
C.V. \% & 3,8934 & 2,4535 & 1,2763 & 1,2195 & 0,0084 & 0,0073 \\
t student & $0,3(*)$ & & $0,3114(*)$ & & $0,5\left(^{*}\right)$ & \\
\hline
\end{tabular}

$(*)$ El valor es significativo a nivel de 0,05 y grados de libertad 22

En la Tabla 4 se aprecia el cálculo del factor de similitud $\left(f_{2}\right)$, evidenciando que en los tres medios de disolución alcanzó valores mayores a 50, y según la normatividad establecida por la Food and Drug Administration, se establecería similitud en los perfiles de disolución por esta comprendido en el rango de 50 - 100, así como presentar al menos 4 puntos de muestreo, y presentar coeficiente de variación porcentual menores al $20 \%$ los primeros puntos y $10 \%$ en los últimos puntos, por tanto, se podría inferir intercambiabilidad entre las formulaciones referente y multifuente de tabletas de prednisona $20 \mathrm{mg}$ comercializadas en el Perú.

Tabla 4. Factor de similitud $\left(f_{2}\right)$ e las tabletas de prednisona $20 \mathrm{mg}$ referente y multifuente a $\mathrm{pH} 1,2 ; 4,5$ y 6,8 .

\section{Factor de similitud $\left(f_{2}\right)$}

\begin{tabular}{lll}
\hline Buffer pH 1,2 & Buffer pH 4,5 & Buffer pH 6,8 \\
\hline 63,9 & 59,5 & 69,9
\end{tabular}

\section{DISCUSIÓN}

Los perfiles de disolución de los productos referente y multifuente en los buffers $\mathrm{pH} 1,2$; 4,5 y 6,8 ; y según el protocolo de estudio de bioequivalencia in vitro establecida por la Organización Mundial de la Salud (OMS), los buffers estarían representando condiciones fisiológicas, simulando así el fluido gástrico, duodenal e intestinal respectivamente. Se aprecia el comportamiento de disolución del producto multifuente en relación al producto de referencia, los cuales mostraron un perfil característico, correspondiente a una completa disolución y a una rápida velocidad ${ }^{(10)}$.

La United State Pharmacopeia 41 indica que no menos del $80 \%$ de la cantidad declarada del producto con principio activo de prednisona $20 \mathrm{mg}$ se disuelve en 30 minutos; y como se evidencia ambas formulaciones cumplen con lo establecido: minuto 30 a pH 1,2 (referente: $85,6 \%$ y multifuente: $83,3 \%$ ), minuto 30 a $\mathrm{pH} 4,5$ (referente: $84,1 \%$ y multifuente: $83,2 \%$ ) y minuto $30 \mathrm{pH} 6,8$ (referente: $83,1 \%$ y multifuente: $81,9 \%)^{(12)}$.

La cinética de disolución de las dos formulaciones en estudio y para cada $\mathrm{pH}$ se realizó con el Criterio de Información de Akaike, que presentó modelos dependientes como orden cero, primer orden, raíz cúbica, Higuchi y Weibull ${ }^{(13)}$. Este método consiste en seleccionar el modelo que minimiza la probabilidad negativa restringida por el número de parámetros, es decir el valor más pequeño señala estadísticamente el mejor proceso de disolución; específicamente tiene como objetivo encontrar el mejor modelo de aproximación para el verdadero proceso de generación de datos desconocidos. En este sentido, el mejor modelo dependiente para ambas formulaciones en los $\mathrm{pH} 1,2 ; 4,5$ y 6,8 fue Weibull, lo que indicaría que este modelo es el que estadísticamente explica mejor el proceso de disolución en cada 
medio señalado, y reflejaría la influencia que pueden tener las condiciones de disolución como medio de disolución y $\mathrm{pH}$, tipo de equipo y velocidad de agitación, no solo sobre la velocidad de disolución, sino también sobre la cinética de liberación de los fármacos ${ }^{(8,14,15)}$.

Del mismo modo, el tratamiento estadístico del tiempo medio de disolución en una distribución $t$ de student bilateral con una $a=0,05$ y 22 grados de libertad; los valores obtenidos fueron: $-1,0$ a $\mathrm{pH} 1,2 ;-0,4$ a $\mathrm{pH} 4,5 ;-1,2$ a $\mathrm{pH} 6,8$. En los tres $\mathrm{pH}$ se obtuvieron valores mayores a $p>0,05$, lo que indicaría que el tiempo medio de disolución del producto multifuente es similar al producto referente. Los resultados evidencian que los excipientes no estarían afectando la velocidad y la extensión de la absorción, aspecto considerado por la Food and Drug administration en el momento que se desea obtener la exención de estudios de bioequivalencia ${ }^{(8)}$.

Respecto al tratamiento estadístico de la eficiencia de disolución, este parámetro expresa la disolución del fármaco, y relaciona el área bajo la curva del perfil de disolución del producto en estudio respecto al área total del rectángulo formado por la disolución teórica del $100 \%$ de la dosis y el intervalo de tiempo de la prueba ${ }^{(9)}$. La distribución t de student bilateral con un $\mathrm{a}=0,05$ y 22 grados de libertad; arrojó valores de 0,2 a pH 1,2;0,3 a pH 4,$5 ; 0,5$ a pH 6,8; y los valores de p fueron 0,800 a pH 1,2; 0,758 a pH 4,5; 0,5830 a pH 6,8 ; estadísticamente no significativos, por lo que se podría inferir similitud entre el producto multifuente y referente.

El factor de similitud $\left(\mathrm{f}_{2}\right)$ en los tres medios de disolución, arrojó valores de 63,9 a pH 1,$2 ; 59,5$ a pH 4,5 y 69,9 a pH 6,8. El $f_{2}$ es una transformación logarítmica del recíproco de la raíz cuadrada de la suma de los cuadrados de los errores, y es una medida de la semejanza en el porcentaje de disolución entre dos curvas, y en la actualidad es adoptado por la Food and Drug Administration y European Agency for the Evaluations of Medicinal Products que establecen la utilización de los porcentajes temporales disueltos de los medicamentos y según la comparación matemática de los perfiles de disolución, cuando presenta valores comprendidos entre $50-100$ indica que hay similitud en las curvas; y por lo tanto es similar el rendimiento del producto multifuente con el producto referente, es decir son productos intercambiables ${ }^{(13,14,15)}$.

En el buffer $\mathrm{pH} 6,8$ se obtuvo el valor más alto del factor de similitud $\left(f_{2}\right)(69,9)$, y reflejaría que medicamentos como prednisona que tiene un $\mathrm{pH}$ de 2,6 - 3,6 se disolvería más fácilmente en un medio alcalino como el $\mathrm{pH} 6,8$. De este modo, pequeñas modificaciones del $\mathrm{pH}$ del medio de disolución pueden hacer variar la solubilidad de una determinada sustancia, aumentar o disminuir la fracción ionizada, que es la más soluble en agua, y con ello las implicancias respecto a la absorción de medicamentos ${ }^{(14,15)}$.

A nivel nacional e internacional, son pocas las investigaciones realizadas en prednisona, es así, que, dentro de los estudios más recientes y relevantes, Henrique, Deris y Antunes realizaron un estudio en Brasil sobre los perfiles de disolución de prednisona, encontrando que los $\mathrm{f}_{2}$ en los medios $\mathrm{pH} 1,2 ; 4,5$ y 6,8 fueron mayores a 50 , con lo cual, se estaría asegurando que la población brasileña acceda a medicamentos con menor precio ${ }^{(11)}$.

Finalmente, el estudio permitió inferir que las tabletas de prednisona $20 \mathrm{mg}$ referente y multifuente comercializados en Perú son similares, por lo que se establecería, intercambiabilidad entre ambas formulaciones, con base en pruebas de perfiles de disolución in vitro, y de esta manera tener alternativas farmacéuticas para el tratamiento de patologías de carácter inflamatorio, cumpliendo con los objetivos estratégicos que presenta el Ministerio de Salud, de que la población, específicamente, aquellos con estratos socioeconómicos bajos, puedan acceder a medicamentos de calidad. Asimismo, los resultados del presente estudio, deberían complementarse con un estudio in vivo, para obtener datos que midan la magnitud (área bajo la curva) y la velocidad de absorción (concentración máxima y tiempo máximo).

\section{Contribuciones de autoría}

ACG y ECS participaron en la concepción y diseño del estudio, recolección de datos, análisis e interpretación de datos, redacción del artículo, revisión crítica del artículo y aprobación de su versión final.

MRL y CAJ participaron en la redacción del artículo. 


\section{Fuentes de financiamiento:}

El presente ha sido financiado por los autores y la Universidad Nacional de Trujillo (UNT). No obstante, el presente artículo no constituye un posicionamiento institucional oficial por parte de la UNT.

\section{Conflictos de interés:}

Los autores declaran no tener conflictos de interés.

\section{REFERENCIAS BIBLIOGRÁFICAS}

1. Huayanay L. Bioequivalencia en medicamentos. Rev Med Hered [revista en internet] 2012 [acceso 15 de julio 2018]; 23(4): 221-2. Disponible en: http://www.scielo.org.pe/scielo.php?script =sci_arttext $\&$ pid $=$ S1018$130 \times 2012000400001 \&$ Ing $=$ es.

2. Estévez F, Parrillo $S$, Cedrés M. Estudios de bioequivalencia in vivo para demostrar la intercambiabilidad de medicamentos. Rev. Méd. Urug. [revista en internet] 2012 [acceso 17 de julio 2018]; 28(3): 165-73. Disponible en: http://www.scielo.edu.uy/scielo.php?script =sci_arttext $\&$ pid $=$ S168803902012000300002\&lng=es.

3. Swami R, Singh $G$, Bhasin $P$, Dureja $H$. In vitro dissolution profile comparison: a tool for biowaivers based on BCS. J Pharm Res. [revista en internet] 2011 [acceso 12 de julio 2018]; 10(2): 73-6. Disponible en: http://www.journalofpharmaceuticalresear ch.org/index.php/kpc/article/download/890 14/67695.

4. Gao Z. In Vitro dissolution testing with flow-through method: A technical note. AAPS PharmSciTech. [revista en internet] 2009 [acceso 15 de julio 2018]; 10(4): 1401-5. Disponible en: https://www.ncbi.nlm.nih.gov/pmc/articles /PMC2799605/

5. Saranadasa $H$, Krishnamoorthy $K$. A multivariate test for similarity of two dissolution profiles. J Biopharm Stat. [revista en internet] 2005 [acceso 15 de julio 2018]; 15(1): 265-78. Disponible en: http://www.ucs. louisiana.edu/ kxk4695/B PS49832.pdf

6. Gomez J, Schaefer U, Casabo V, Lehr T, Lehr C. Statistical comparison of dissolution profiles to predict the bioequivalence of extended release formulations. The AAPS Journal. [revista en internet] 2014 [acceso 10 de julio 2018]; 16(4): 791-801. Disponible en: https://www.ncbi.nlm.nih.gov/pmc/articles /PMC4070268/

7. Food and drug administration (FDA). Guía para la Industria: Pruebas de disolución de formas de dosificación oral sólidas de liberación inmediata. [monografía en internet] 2010. [acceso 14 de abril del 2018]. Disponible: http://www.fda.gov/Drugs/GuidanceCompli
anceRegulatoryInformation/Guidances/ucm 200707.htm

8. Pérez $M$, Orobio $Y$, Baena $Y$. Estudio comparativo de la liberación in vitro de metformina, a partir de dos productos multifuente de liberación inmediata, comercializados en Colombia. Rev. Colomb. Cienc. Quím. Farm. [revista en internet] 2013 [acceso 21 de julio 2018]; 42 (2): 169-89. Disponible en: http://www.scielo.org.co/pdf/rccqf/v42n2/ v42n2a02.pdf

9. Medina $R$, Hurtado $M$, Cortés $A$, Domínguez M. Disolución comparativa de indometacina en cápsulas utilizando los Aparatos 1 y 4 USP. Rev. mex. cienc. farm [revista en internet] 2012 [acceso 15 de julio 2018]; 43(3): 72-80. Disponible en: http://www.scielo.org.mx/scielo.php?script =sci_arttext\&pid=S1870$01952012000300008 \&$ Ing $=$ es.

10. World Health Organization. Proposal to waive in vivo bioequivalence requirements for WHO Model list of Essential Medicines immediate-release, solid oral dosage forms. Technical Report Series, No 937, 40th Report, Annex 8 of WHO Expert committee on specifications for pharmaceutical preparations. [monografía en internet] Génova; 2006 [acceso 14 de abril del 2018]. Disponible en: http://apps.who.int/prequal/info_general/ documents/TRS937/WHO_TRS_937_a nnex8_eng.pdf

11. Henrique L, Deris L, Antunes H. Prednisone raw material characterization and formulation development. Braz. J. Pharm. Sci. [revista en internet] 2017 [acceso 15 de julio 2018];53(4): 1-14. Disponible en: http://www.scielo.br/scielo.php?script=sci_ arttext\&pid $=$ S1984$82502017000400604 \&$ Ing $=$ en.

12. Farmacopea de los Estados Unidos de América - USP 41 - NF 35. Vol. 3 [libro electrónico]. Rockville; The United States Pharmacopeial Convention; 2017. p. 598990.

13. Navarro G, Cabral P. Aplicación de métodos modelo-dependiente y modeloindependiente en el desarrollo de una formulación de comprimidos de captopril. Rev. Colomb. Cienc. Quím. Farm. [revista en internet] 2009 [acceso 18 de julio 2018]; 38 (1): 19-30. Disponible en: 
http://www.scielo.org.co/pdf/rccqf/v38n1/ v38n1a02.pdf

14. Moellenhoff $K$, Dette $H$, Kotzagiorgis E, Volgushev S, Collignon O. Regulatory assessment of drug dissolution profiles comparability via maximum deviation. Stat Med. [revista en internet] 2018 [acceso 18 de julio 2018]; 37(20):2968-2981. Disponible en: https://www.ncbi.nlm.nih.gov/pubmed/29 862526
15. Simionato LD, Petrone $L$, Baldut $M$, Bonafede SL, Segall AI. Comparison between the dissolution profiles of nine meloxicam tablet brands commercially available in Buenos Aires, Argentina. Saudi Pharm J. [revista en internet] 2018 [acceso 18 de julio 2018];26(4):578-584. Disponible en: https://www.ncbi.nlm.nih.gov/pmc/articles /PMC5961619/ 